\title{
ULTRA HIGH DILUTION OF ZINC IN THE MANAGEMENT OF REFRACTORY PARKINSON'S DISEASE-A CASE REPORT
}

\author{
Dr. DEEPTHI GILLA ${ }^{1}$, Dr. S.G.S. CHAKRAVARTHY \& Dr. SREELAKSHMY S.R ${ }^{2}$ \\ ${ }^{I}$ Research Officer (H)/ Asst. Professor, Dept. of Psychiatry, NHRIMH, Kottayam, India
}

*Associate Professor, Dept. of Medicine, National Homoeopathy Research Institute in Mental Health (NHRIMH), Kurichy, Kottayam, Kerala, India

${ }^{2}$ Junior Research Fellow, NHRIMH, Kottayam, India

\begin{abstract}
Background: Parkinson's disease (PD) is one of the most common, disabling neuro-degenerative disorders. The disease has a significant clinical impact on patients, families, and caregivers through its progressive degenerative effects on mobility and muscle control. Available treatments for PD have varied results. Although there are anecdotal reports of improvement with Homoeopathy, there is a dearth of literature concerning usefulness in management of PD

Objectives: To assess the usefulness of ultrahigh dilution of Zinc in the management of PD.

Methods: A case of PD under standard care and refractory to treatment visited Out- Patient Department and was assessed with and Unified Parkinson's Disease Rating Scale (UPDRS). As per the classical Homoeopathic guidelines Zincum metallicum 200 was prescribed after Repertorization.

Results: UPDRS total score of 112 at baseline turned to 40 at the end of 1 year and 7 at the end of two years, in spite of reduction in the conventional medicines. Patient was on Stage 3 of Modified Hoehn and Yahr staging at the baseline and turned to Stage $O$ in duration of 21 months. SEADL score has turned from $40 \%$ to $100 \%$.

Conclusion: Homoeopathic medicine Zincum met. is a valuable adjuvant in the management of Parkinson's disease.

KEYWORDS: Parkinson's disease, Unified Parkinson's Disease Rating Scale (UPDRS), Homoeopathy \& Zincum metallicum
\end{abstract}

Received: Jan 03, 2021; Accepted: Jan 23, 2021; Published: Feb 04, 2021; Paper Id.: IJMPSJUN20212

\section{INTRODUCTION}

Parkinson's disease (PD) is a chronic, progressive Neuro-degenerative disease characterized by both motor and non-motor features. It was first described by Dr. James Parkinson in 1817 as a "shaking palsy." ${ }^{11]}$ Parkinson's disease (PD) affects 1-2 per 1000 of the population at any time. PD prevalence is increasing with age and PD affects $1 \%$ of the population above 60 years. ${ }^{[2]}$

Parkinsonism is a clinical syndrome, which is characterized by bradykinesia, rigidity, rest tremor, and postural instability. The patients also have a high incidence of balance impairments, constipation, hypotension, erectile dysfunction, urinary dysfunction, dizziness, fatigue, depression, and anxiety before 5 years of diagnosis. ${ }^{[3]}$

Idiopathic Parkinson disease (PD) is the most common cause of this syndrome, though there are several other important etiologies that must be considered. These include the atypical Parkinsonian disorders multiple system atrophy (MSA), dementia with Lewy Bodies (DLB), Progressive supra nuclear palsy (PSP), and Cortico 
basal syndrome (CBS); as well as secondary causes of Parkinsonism like some medications. These various disease entities may be distinguished based on key clinical features, which is critical for the purposes of diagnosis, treatment, and prognosis. ${ }^{[4][5]}$

Parkinson's disease (PD) is caused mainly by lack of dopamine in the brain due to degeneration of substantia nigra and its associated cortical neurons. Dopamine is a neurotransmitter involved in movement, motivation, memory and other functions. ${ }^{[6]}$ With clear evidence for concurrent abnormalities in the basal ganglia, thalamus and cortex, Parkinsonism is now recognized as a disease of a distributed brain network. ${ }^{[7]}$ A genetic basis can be seen in $>10 \%$ of Young onset PD individuals, and the proportion of genetically defined cases rises to $>40 \%$ if the onset of disease is before 30 years of age. ${ }^{[8]}$ Environmental influences such as smoking, caffeine consumption, and pesticide exposure have been postulated to alter the risk of PD development, although the role of these remains unclear. ${ }^{[9]}$

MRI should be performed as a standard procedure in all patients presenting with a form of Parkinsonism. Parkinson disease is a clinical diagnosis, and magnetic resonance imaging (MRI) may be used only to exclude other causes. ${ }^{[10]}$ Suitable efforts should be performed to achieve accurate diagnosis, communicate a plausible prognosis to the patient and family, and proceed with the best therapeutic interventions. Remarkable progress has been made in the last two decades in the field of genetics, pathophysiology, and clinical imaging, but the diagnosis of PD still sits inevitably on clinical skills and exploration, which emphasizes the importance of a solid clinical knowledge about the disease. ${ }^{[11]}$

The Unified Parkinson's Disease Rating Scale (UPDRS) is a comprehensive tool used for motor, non-motor symptoms, mental functioning, mood, social interaction and also accounts for cognitive disabilities, daily activities and treatment complications. It is useful for a longitudinal follow up of case of PD. ${ }^{[12]}$

Unlike other neurodegenerative diseases, idiopathic Parkinson's disease has effective treatments that mitigate symptoms. Medications can improve day-to-day function and, in cases where medication does not give a sustained benefits or has significant side effects, treatments like deep brain stimulation result in improved quality of life ${ }^{[13]}$ There are many medical options for the treatment of PD but levodopa remains the mainstay. ${ }^{[14]}$ As the disease progresses, additional nonparkinsonian symptoms can be of concern. Furthermore, the side effects of Parkinson medications may necessitate the involvement of other medical specialists. ${ }^{[15]}$

\section{CASE REPORT}

2.1 Client Information: Mrs. NK, 57 years, married female client, and an ex-municipal councillor, visited outpatient department of (Blinded for review) along with her husband.

2.2 Presenting Complaints: with tremors of both hands more at rest, especially right side. The tremors are aggravated during emotional excitement and while writing or doing fine work. She has difficulty in holding things and gait imbalance while walking and unable to do her routine works like eating with a spoon, dressing up, cooking and other household works.

2.3 History of present illness: Complaints gradually started 14 years back. She initially noticed a mild trembling in her right hand, awkwardness and stiffness in upper limbs while swaying and driving car. She approached a physician and started medication, but the symptoms kept on progressing. She felt depressed of her health condition due to disturbance in occupational works and complaints made her feel embarrassed in the public. She approached a Neurophysician and 
underwent suitable investigations and her condition was diagnosed as Idiopathic Parkinson's disease. She is currently on Tab. Pramipexole -QID, T. Rasalect $0.5 \mathrm{mg}$ OD and T. Pacitane $2 \mathrm{mg}$ BD, which she is using since 10 years, the dosage was modified by the neurophysician as per the condition of the patient.

For the past 3 months, complaints worsened in spite of regular medications, her quality of life is greatly affected and so she opted for alternative treatment. She is a known case of NIDDM since $31 / 2$ years and under allopathic medication. (Metformin 0-0-1)

2.4 Past History: She suffered from Hepatitis at the age of 35 years, treated with folk-medicine and relieved. She had a past history of recurrent pruritus vulva and leucorrhoea since the age of 45 years for which she used several internal medications and external applications for 8-10 years.

2.5 Family History: Positive Family History of Diabetes (Mother), Myocardial infarction (Father) and Brother committed suicide due to Depression.

2.6 Mental Generals (Pre-morbid Personality): Mrs. NK was an out-going, cheerful and strong-willed person. She was very studious and all-rounder in all academic and extra-curricular activities. She had good leadership qualities in academics and in sports also. She was easily irritated especially from noises. She easily gets angered by contradiction, and expresses by shouting especially on subordinates.

She was working as municipal counsellor for past few years, but this time she didn't nominate herself due to depressed and embarrassed feeling of her health condition in front of society. She is courageous, hard-working and duty minded. She feels so sad about her disease especially because she cannot carry on her professional works. She is a bit domineering personality and expects that everybody should obey her. Her Inter-social and familial relationship is harmonious.

\subsection{Physical Generals:}

Physical make up- moderately built, fair complexioned.

Appetite: good; Thirst: moderate (2-3 litres /day) Bowel movements: Regular.

Desires: Meat, especially beef, Tapioca, Jack fruit and has aversion to Sweets

Perspiration: Profuse all over the body Sleep: Sleeplessness for past few months.

Thermals: Chilly.

\subsection{Physical Examination:}

2.8.1 General Examination: Gait - Shuffling gait with stooped posture on walking.

Vital signs: Temperature- $98.2^{\circ} \mathrm{F}$, Pulse- 74 beats /min; Respiratory rate- 20/min, Blood Pressure- 130/70 mmHg.

No signs of Pallor/ Icterus/ Lymphadenopathy / Clubbing/ Cyanosis/ Oedema.

\subsubsection{Nervous System Examination:}

2.8.2.1 Higher functions: Conscious, Coherent, Depressed (about illness), Moderate Sleeplessness, No signs of Dementia Hallucinations, illusions, delusions. 
2.8.2.2 Cranial Nerves: All Cranial Nerves functioning is normal

2.8.2.3 Sensory system: All sensations were intact and normal.

2.8.2.4 Motor system: Stooped posture with unable to maintain postural stability, Difficulty in walking with shuffling gait, Masked facial Expressions, Monotonous, and Slurred speech (understandable). There was Resting Tremors, More on Right hand with severe slowness of Movements. Reduced Leg Movements with stiffness, Rt > Lt. Cogwheel Rigidity in both upper and lower limbs with Moderate impaired finger tapping ability. All Reflexes are elicited bilaterally. Myerson's sign positive. Deep tendon reflexes (Knee jerk, Ankle jerk) are Slightly exaggerated more on Right side. Other findings of Motor system like Bulk, Tone and Strength are normal bilaterally.

2.8.2.5 Symptoms of Autonomic dysfunction: Excessive Sweating, Sialorrhea are present.

\section{DIAGNOSIS AND ASSESSMENT: IDIOPATHIC PARKINSON'S DISEASE}

The patient was assessed at baseline with Unified Parkinson's Disease Rating Scale (UPDRS). Unified Parkinson's Disease Rating Scale (UPDRS): 112/ 199

Modified Hoehn and Yahr staging: Stage 3

Schwab and England activities of Daily Living Scale: $40 \%$

Case was taken as per the Homoeopathic guidelines and Zincum metallicum 200-1 dose was prescribed after Repertorization and reference to Materia medica. The repertorial sheet of the case is shown in Figure no.1.

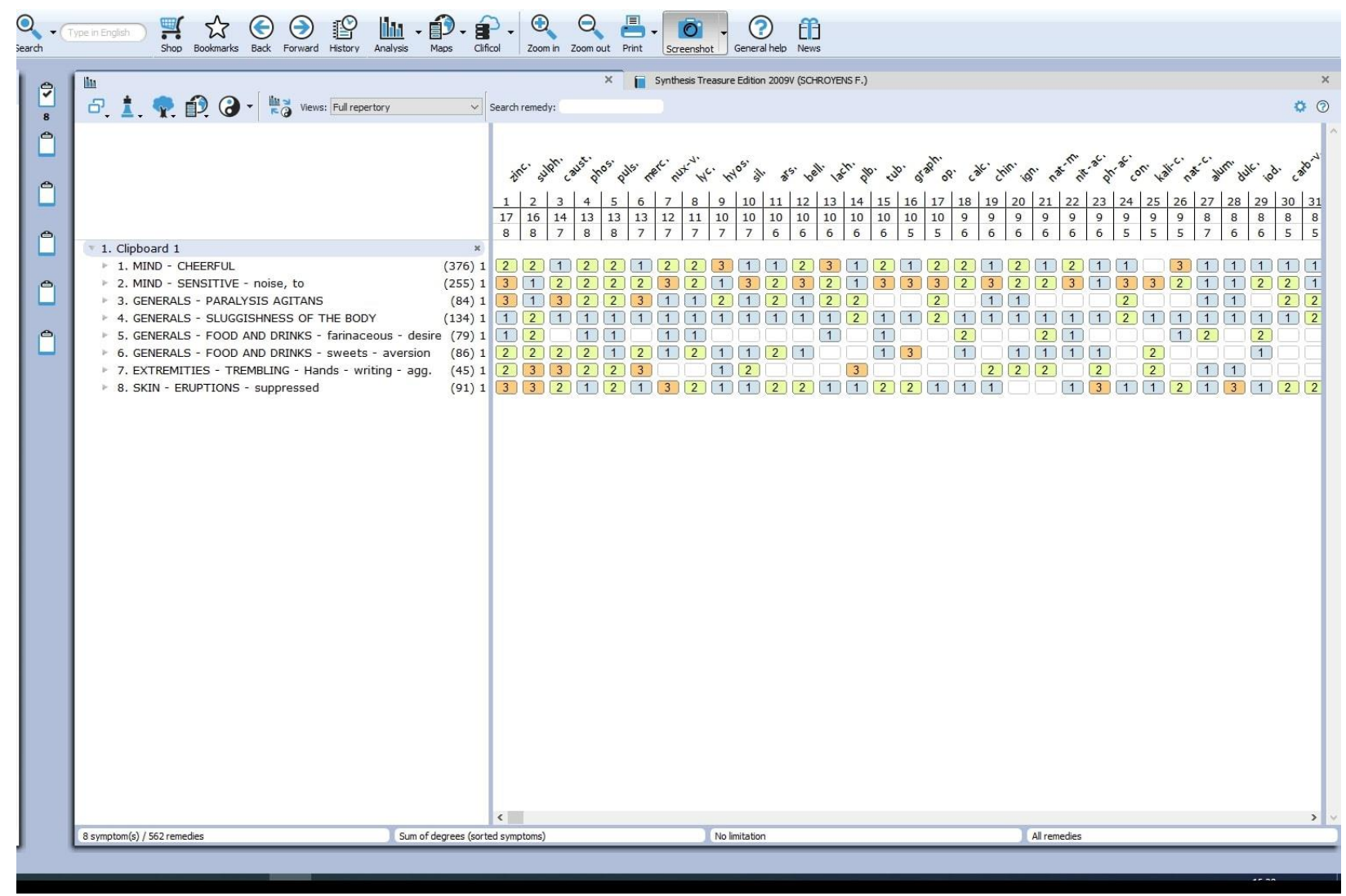

Figure 1: Repertorization Chart 


\section{RESULTS}

UPDRS total score of 112 at baseline turned to 40 at the end of 1 year and 7 at the end of two year, in spite of reduction in the dosage of conventional medicines. Patient was on Stage 3 of Modified Hoehn and Yahr staging at the baseline and turned to Stage O. On assessing with Schwab and England Activities of Daily Living Scale, the Score has turned from $40 \%$ to $100 \%$. Changes in SEADL scale are shown in Figure no. 2.

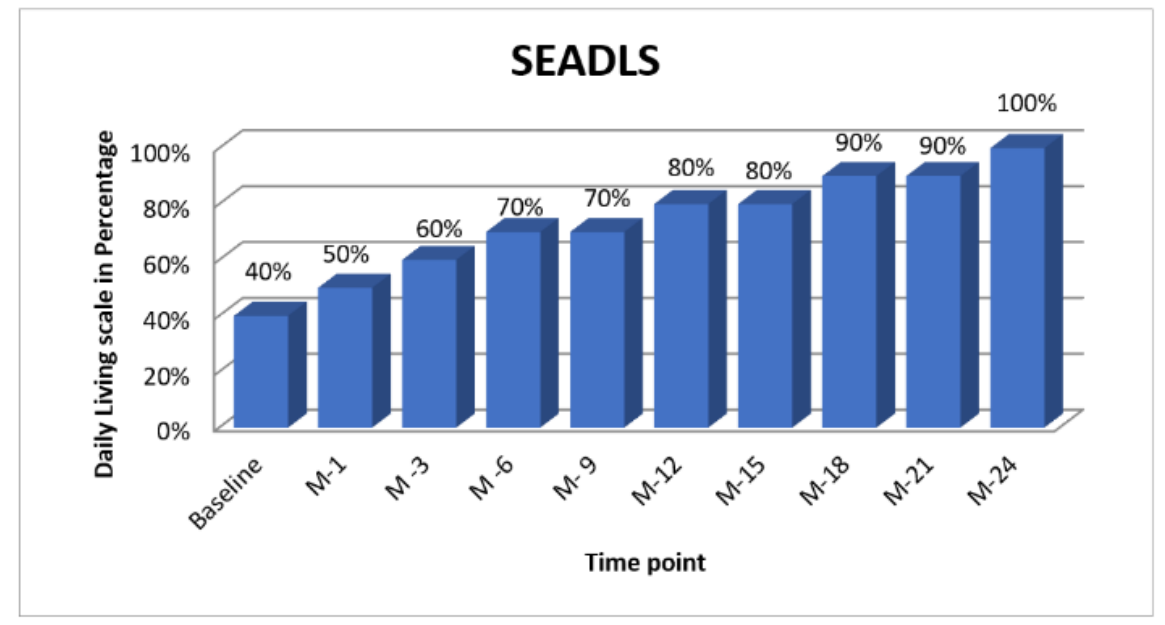

Figure no.2 Improvement in the Schwab and England Activities of Daily Living during follow up

Figure 2

The follow up of the patient has been presented in Table no. 1 and the changes in total UPDRS scores have been presented in Figure no.3.

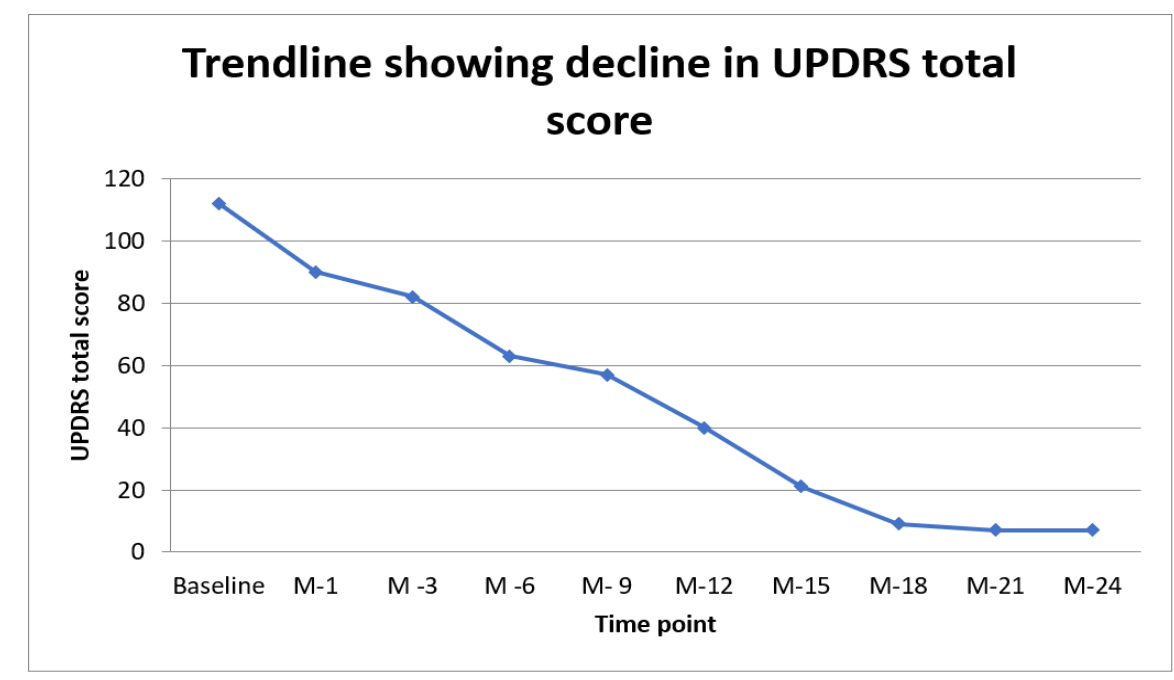

Figure no.3 UPDRS - Unified Parkinson's Disease Rating Scale Total Score

Figure 3 
There was progressive improvement in individual symptom domain scores of UPDRS in the consecutive follow up visits, which are represented in Figure no.4.

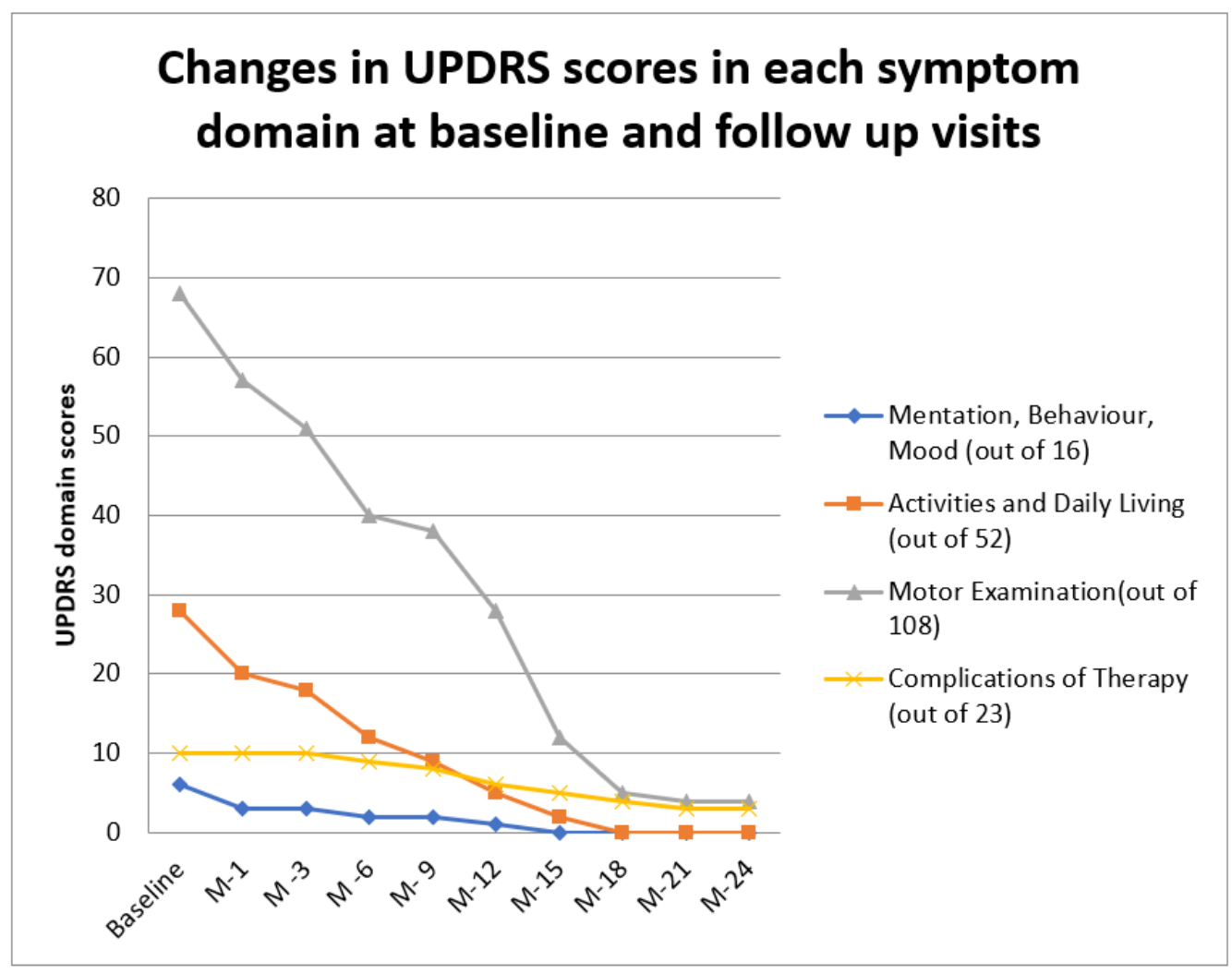

Figure no.4 UPDRS Scores in each symptom domain at baseline and follow up visits

Figure 4

Table 1: Follow Up of the Case with Treatment

\begin{tabular}{|c|c|c|c|c|}
\hline Sl. No. & Date & Symptoms & Prescription & Remarks \\
\hline Baseline & 16.10 .18 & $\begin{array}{l}\text { Tremors }<\text { during anxiety, tremors more } \\
\text { on right hand } \\
\text { Slowness in doing activities. } \\
\text { Trembling of hand while writing. } \\
\text { Difficulty in holding things and difficult } \\
\text { gait. Inability to do daily activities and } \\
\text { household activities. Slurred speech. } \\
\text { Sleeplessness. }\end{array}$ & $\begin{array}{l}\text { 1. Zincum met } \\
\text { 200-1dose } \\
2 . \quad \text { Rubrum-1 } \\
\text { month }\end{array}$ & $\begin{array}{l}\text { Baseline assessment done } \\
\text { with UPDRS. } \\
\text { (Patient is using } \\
\text { T. Pramipexole -QID, } \\
\text { T. Rasalect } 0.5 \mathrm{mg} \text { OD } \\
\text { T. Pacitane } 2 \mathrm{mg} \mathrm{BD} \text { ) }\end{array}$ \\
\hline 1 & 13.11 .18 & $\begin{array}{l}\text { Tremors reduced. Slurring of speech } \\
\text { reduced. Gait is better. } \\
\text { Dry Cough since } 1 \text { week due to } \\
\text { exposure to cold air. Hoarseness of } \\
\text { voice < talking. }\end{array}$ & $\begin{array}{ll}\text { 1. } & \text { Bryonia 30- } \\
4 \text { dose } & \\
2 . & \text { Rubrum }-1 \\
\text { month } & \end{array}$ & As an Acute Rx for cough. \\
\hline 2 & 11.12 .18 & $\begin{array}{l}\text { Cough relieved. } \\
\text { Hoarseness of voice reduced. Facial } \\
\text { expressions are better. Pleasant mood. } \\
\text { Tremors reduced. }\end{array}$ & $\begin{array}{l}\text { 1. Rubrum - } 1 \\
\text { month }\end{array}$ & $\begin{array}{l}\text { T. Pramipexole }- \text { (reduced to } \\
\text { TID) } \\
\text { T. Rasalect } 0.5 \mathrm{mg} \text { OD } \\
\text { T. Pacitane } 2 \mathrm{mg} \mathrm{BD}\end{array}$ \\
\hline
\end{tabular}




\begin{tabular}{|c|c|c|c|c|}
\hline 3 & 17.01 .19 & $\begin{array}{l}\text { Tremor increased in whole body, more } \\
\text { on Right hand since } 1 \text { week. Speech- } \\
\text { better } \\
\text { Sleep - disturbed. } \\
\text { Hoarseness of voice persists. }\end{array}$ & $\begin{array}{lr}1 . & \text { Zincum met } \\
\text { 200/1 dose } \\
2 . \quad \text { Rubrum }-1 \\
\text { month }\end{array}$ & $\begin{array}{l}\text { History of death of neighbour } \\
\text { last week, symptoms } \\
\text { aggravated after that. }\end{array}$ \\
\hline 4 & 27.04 .19 & $\begin{array}{l}\text { Tremors better. } \\
\text { General weakness reduced. Hoarseness } \\
\text { of voice reduced. Felt comfortable to do } \\
\text { household work. Sleep- Refreshed. Able } \\
\text { to go to her occupation regularly. } \\
\text { Itching eruption appeared on right } \\
\text { dorsum of foot. }\end{array}$ & $\begin{array}{l}\text { 1. Zincum met } \\
\text { 200/1 dose (s.o.s) } \\
2 . \quad \text { Rubrum-3 } \\
\text { months }\end{array}$ & $\begin{array}{l}\text { T. Pramipexole -reduced to } \\
\text { BD, } \\
\text { T. Rasalect - stopped } \\
\text { T. Pacitane } 2 \mathrm{mg} \mathrm{BD} \\
\text { FBS-181mg/dl } \\
\text { HbA1c-6mg\% } \\
\text { Triglycerides-391 mg/dl }\end{array}$ \\
\hline 5 & 27.07 .19 & $\begin{array}{l}\text { Tremor slightly increased since } 3 \text { days. } \\
\text { Can do household work. } \\
\text { Going job regularly. }\end{array}$ & $\begin{array}{l}\text { 1. } \quad \text { Zincum met } \\
200 / 2 \text { dose } \\
\quad 1 \text { dose (s.o.s) } \\
2 . \quad \text { Rubrum }-1 \\
\text { month }\end{array}$ & $\begin{array}{l}\text { T. Pramipexole -BD, } \\
\text { T. Pacitane } 2 \mathrm{mg} \mathrm{BD}\end{array}$ \\
\hline 6 & 24.10 .19 & $\begin{array}{l}\text { Tremor in upper extremities reduced } \\
\text { Difficulty to walk reduced. } \\
\text { Confidence- improved. She is able to } \\
\text { drive. }\end{array}$ & $\begin{array}{ll}1 . & \text { Rubrum-1 } \\
\text { month } & \end{array}$ & $\begin{array}{l}\text { T. Pramipexole -BD, } \\
\text { T. Pacitane } 2 \mathrm{mg} \text { BD }\end{array}$ \\
\hline 7 & 18.01 .20 & $\begin{array}{l}\text { Aggravation of complaints since } 2 \\
\text { weeks. } \\
\text { History of cough and sneezing, now } \\
\text { relieved. }\end{array}$ & $\begin{array}{l}1 . \\
1 \mathrm{M} / 1 \text { dose } \\
2 . \quad \text { Rubrum }-3 \\
\text { months }\end{array}$ & $\begin{array}{l}\text { FBS-122 mg/dl. } \\
\text { T. Pramipexole -BD, } \\
\text { T. Pacitane } 2 \mathrm{mg} \text { BD }\end{array}$ \\
\hline 8 & 25.04 .20 & $\begin{array}{l}\text { Marked improvement. } \\
\text { Speech and gait- much better }\end{array}$ & $\begin{array}{l}\text { 1. Rubrum-3 } \\
\text { months }\end{array}$ & $\begin{array}{l}\text { T. Pramipexole -OD, } \\
\text { T. Pacitane } 2 \mathrm{mg} \mathrm{BD}\end{array}$ \\
\hline 9 & 7.07 .20 & $\begin{array}{l}\text { Tremor - Nil } \\
\text { She can do her daily routine without } \\
\text { assistance. Smiling. } \\
\text { Writing improved } \\
\text { Fine activities -Improved }\end{array}$ & $\begin{array}{l}\text { 1. Rubrum-3 } \\
\text { months }\end{array}$ & $\begin{array}{l}\text { T. Pramipexole -stopped and } \\
\text { T. Pacitane } 2 \mathrm{mg} \text { BD as it is }\end{array}$ \\
\hline 10 & 7.10 .20 & $\begin{array}{l}\text { Marked improvement. } \\
\text { Tremor- Nil. } \\
\text { Confidence improved. } \\
\text { Writing better now. } \\
\text { Able to drive and do her daily activities. }\end{array}$ & $\begin{array}{l}\text { 1. Rubrum-3 } \\
\text { months }\end{array}$ & $\begin{array}{l}\text { Now she is under } \\
\text { Pacitane OD }\end{array}$ \\
\hline
\end{tabular}

\section{DISCUSSIONS}

Increasing evidence points to biological sex as an important factor in the development and phenotypical expression of Parkinson's disease (PD). Risk of developing PD is twice as high in men than women, but women have a higher mortality rate and faster progression of the disease. ${ }^{[20]}$ This female client had gradual progression of disease, following an abrupt rapidity. Hence limiting the progression of disease is very crucial for this patient, which could be achieved by Homoeopathy.

A report of 11 cases on Individualized Homoeopathic management in Neurological and Psychiatric maladies reported Ignatia 200 followed by Natrum mur 200 eliminated symptoms of PD, but a follow up of 6 months only was put forward in this case. ${ }^{[17]}$ 
Homoeopathic remedies act on Neurological disorders effectively and many remedies like Zincum met, Merc sol, Rhus tox, Nat mur are found to be useful in relieving symptoms of Parkinsonism. Many Homoeopathic Literatures evidence the remedies like Lolium temulentum, Ambra grisea, Rhus toxicodendron, Gelsemium, Baryta Carb, Mercurius, Argentum Nitricum, Agaricus Muscarius, Cocculus indicus, Lathyrus sativus in functional tremor ${ }^{[18]}$

A meta-analysis on Parkinson's disease and Zinc showed that the serum Zinc levels were significantly lower in PD patients compared with healthy controls. Zinc is an essential trace element in the human body and is abundantly in the hippocampus and cerebral cortex and its deprivation results in changes in behaviour, learning, memory and emotional stability leading to disorders such as PD, Alzheimer's disease and amyotrophic lateral sclerosis. ${ }^{[19]}$ The effect of ultrahigh dilution of Zinc on PD has been illustrated through this case.

In a study on rat model it was found that Zincum metallicum may be helpful in slowing down injury in Parkinsonism and could be a beneficial drug for the prevention of PD. Zincum metallicum, produces symptoms mentioned in Homoeopathic Materia Medica which are akin to PD on which basis it might be considered as one at the intermediate to treat the disease. ${ }^{[20] .}$ In this case also Zincum met shows remarkable effect on the symptoms of PD, but whether the clinical effect is because of individualization or due to the specific action of Zincum is yet to be understood.

The indications for Zincum met in PD are - Violent trembling (twitching) of the whole body especially after emotions, Chorea from suppressed eruptions; Trembling of hands while writing, during menses, Lameness, weakness, trembling and twitching of various muscles, Feet in continued motion- cannot keep still, Aggravation after fright, grief and anger, Amelioration after eating and discharges. ${ }^{[21]}$

As PD is a chronic, Neuro-degenerative disease it is imperative to understand that the patient requires long-term treatment, and Homoeopathic ultrahigh dilutions as an adjunctive are found to be effective. How effectively homoeopathic medicines can be useful as stand-alone treatment is yet to be explored.

\section{CONCLUSIONS}

Homoeopathic medicine Zincum met is a valuable adjuvant in the management of Parkinson's disease. Whether this clinical effect is due to the individualized prescription or due to the specific action of Zinc is yet to be understood. Scientific studies with rigorous designs are necessary to assess the effectiveness of Individualized Homoeopathic medicines in PD.

\section{ETHICAL CONSIDERATIONS}

The patient consented voluntarily for publishing the case report but the identity is not disclosed based on ethical guidelines.

\section{ACKNOWLEDGEMENTS}

We express gratitude to Mrs. Resmy. R, Statistical Assistant of NHRIMH for helping in the presentation of data.

\section{CONFLICTS OF INTEREST}

None declared.

\section{FUNDING AND SPONSORSHIP}

Nil 


\section{REFERENCES}

1. DeMaagd G, Philip A. (2015). Parkinson's Disease and Its Management: Part 1: Disease Entity, Risk Factors, Pathophysiology, Clinical Presentation, and Diagnosis. P T, 40(8):504-532.

2. Tysnes OB, Storstein A. (2017). Epidemiology of Parkinson's disease. J Neural Transm (Vienna), 124(8):901-905. doi:10.1007/s00702-017-1686-y

3. Dr. Anette Schrag.et.al. (2015). "Prediagnostic symptoms of Parkinson's disease in primary care; a case control study" The Lancet Neurology; Volume 14, Issue-1, P57-64, January 01

4. Keener AM, Bordelon YM. (2016) Parkinsonism. Semin Neurol, 36(4):330-334. doi:10.1055/s-0036-1585097

5. Levin J, Kurz A, Arzberger T, Giese A, Höglinger GU. (2016). The Differential Diagnosis and Treatment of Atypical Parkinsonism. Dtsch Arztebl Int, 113(5):61-69. doi:10.3238/arztebl.2016.0061

6. Fatemeh N. Emamzadeh and Andrei Surguchov. (2018). Parkinson's Disease: “Biomarkers, Treatment, and Risk Factors”, Frontiers in Neuroscience; doi: 10.3389/fnins.2018.00612

7. Galvan A, Wichmann T. (2008). Pathophysiology of parkinsonism. Clin Neurophysiol, 119(7):1459-1474. doi:10.1016/j.clinph.2008.03.017

8. Radhakrishnan DM, Goyal V. (2018) "Parkinson's disease"- A review, Department of Neurology, All India Institute of Medical Sciences, New Delhi, India; Volume: 66, Issue: 7, Page : 26-35.

9. Stoker TB, Greenland JC. (2018). Parkinson's Disease: Pathogenesis and Clinical Aspects, Brisbane (AU): Codon Publications

10. Philippe Rizek. M.D et.al.(2016). “An update on the diagnosis and treatment of Parkinson's disease” CMAJ, 188(16): $1157-1165$.

11. Massano J, Bhatia KP.(2012) Clinical approach to Parkinson's disease: features, diagnosis, and principles of management. Cold Spring Harb Perspect Med. 2(6):a008870. doi:10.1101/cshperspect.a008870

12. Movement Disorder Society Task Force on Rating Scales for Parkinson's Disease. ( 2003) .The Unified Parkinson's Disease Rating Scale (UPDRS): status and recommendations. Mov Disord;18(7):738-750. doi:10.1002/mds.10473

13. Hayes MT. (2019) Parkinson's Disease and Parkinsonism. Am J Med,132(7):802-807. doi:10.1016/j.amjmed.2019.03.001

14. Reich SG, Savitt JM. (2019). Parkinson's Disease. Med Clin North Am.;103(2):337-350. doi:10.1016/j.mcna.2018.10.014

15. Csoti I, Jost WH, Reichmann H.(2016) Parkinson's disease between internal medicine and neurology. J Neural Transm (Vienna). 123(1):3-17. doi:10.1007/s00702-015-1443-z

16. Cerri S, Mus L, Blandini F.(2019). Parkinson's Disease in Women and Men: What's the Difference?. J Parkinsons Dis, 9(3):501-515. doi:10.3233/JPD-191683

17. Jariwala H, Patel S, Prajapati R, Feral Daruwala R.(2019). Individualized Homoeopathic management in neurological and psychiatric maladies: A report of eleven cases. Journal of Preventive Medicine and Holistic Health, July-December, 2019;5(2):110-118.

18. Robin Murphy.(2004). Homoeopathic Medical Repertory - Second Revised Edition - Reprint 2004.B. Jain Publishers (P) Limited, New Delhi

19. Ke du et.al.(2017). "Decreased Circulating Zinc levels in Parkinson's disease- A meta-analysis study" Scientific Reports 
20. Andleeb khan et.al.(2019). "Protective effect of Zincum met on Rat model of Parkinson's Disease", Indian journal of Research in Homoeopathy.

21. Pal P P, (2019) Parkinson's disease and Homeopathic Zinc, International Journal of Homoeopathic Sciences, 3(1): 74-75 